tant roles to play in work upon dynamical systems. Chaotic motion in systems of finite order provides some hope that an understanding of turbulence might be within reach, a motivation which underlies many of the papers in the books under review. A solution of this particular problem still escapes us, however.

Because the study of chaos has so many roots, the early sources appear to be distributed as randomly among the journals as the phase points in the phase space of a chaotic system. There are some textbooks and good review articles on various topics, but because none of them adequately covers the whole field it is not easy to get an overall view of the subject.

Does Hao Bai-Lin's anthology of some of the more original papers improve the situation? Yes, with qualifications. The papers of Kolmogorov on the preservation of order in Hamiltonian systems and of Landau and of Hopf on the problem of turbulence are classics in their fields, and are difficult for the general-reader to find; their inclusion is to be welcomed.

In other respects this collection can be compared to Predrag Cvitanović's, which also contains about 40 papers in the same general area. Surprisingly, the two books have only six papers in common. We can find out in both how Lorenz was led to doubt the feasibility of very long-range weather prediction, and how he related his differential equations in three dimensions to a one-dimensional map, we can admire May's introduction to simple systems with complicated dynamics and follow through to Feigenbaum's classic exposition of renormalization and universality. We find Metropolis, Stein and Stein's use of symbol sequences to study maps on the interval, Henon's numerical study of second-order quadratic maps with attractors, and Crutchfield and Huberman's studies of the effect of external noise. Neither editor does justice to Hamiltonian systems, however, whose properties are illustrated by the behaviour of the orbits of iterated area-preserving maps. Omitted from both collections are Greene's classic paper on the standard map and Henon's on the quadratic map.

Each book has an introduction, and those who like lively informality will prefer Cvitanović's. But both are useful collections, of great value for researchers in related fields, and the earlier papers provide valuable insight into the motivation behind more recent research. Libraries and specialists would do well to get hold of the two of them; for others Universality in Chaos is to be preferred on grounds of value for money. If Hao BaiLin's book is reasonably priced in China, it should attract a large new population of scientists to the burgeoning field of chaos in dynamical systems.

Ian Percival is a Professor in the School of Mathematical Sciences at Queen Mary College, University of London, Mile End Road, London EI $4 N S, U K$.

\section{Disappearing acts in the oceans}

\author{
Peter J. Smith
}

Lost Islands: The Story of Islands That Have Vanished from Nautical Charts. By Henry Stommel. University of British Columbia Press/Academic and University Publishers, London: 1985. Pp.146. \$30.50, $£ 30.50$.

As RECENTLY as 1982, the offices of Lufthansa Airlines in London, Boston and New York were displaying rather handsome globes upon which was to be found Ganges Island, located about a third of the way between Japan and Hawaii. The most startling fact about Ganges, however, is that it has never existed. During the nineteenth century, six sightings of land at about $31^{\circ} \mathrm{N}, 154^{\circ} \mathrm{E}$ were reported; and on the grounds that such a potential danger to shipping could not be ignored, the supposed island was included on hydrographic charts despite the innumerable failures of Pacific Mail steamers to confirm its reality. The nonexistent island was still on the International Hydrographic Bureau's list of possible navigational hazards as late as 1932 and was not deleted from British Admiralty charts until 1941.

This is an example of what Stommel means by a lost island, although "lost" is perhaps hardly the most appropriate word to describe something that was never really found in the first place. Be that as it may, the version of Admiralty Chart 2683 dated 1875 contained no fewer than 142 of them in the Pacific alone. Some years later, Sir Frederick Evans, newly appointed hydrographer to the Royal Navy, decided to consign 123 pin-pricks of land to oblivion, including three genuine islands that had later to be reinstated. But many more throughout the world were to cling tena- ciously to their ghostly life; and one (Thompson Island) is still to be found on a current US Defense Mapping Agency chart (last revised 1965) in spite of having beer expunged from the British Admiralty maps as long ago as 1931 .

That imaginary islands should still have been entering the charts in the nineteenth century (the starting point of Stommel's survey) is not surprising. Many were genuine mistakes arising from the continued inability to determine longitude with any accuracy. A real island could easily acquire an illusory twin, or even multiply into an archipelago, as a result of incorrect longitudes assigned by successive observers. Other fictitious islands were born of reporting, charting and typographical errors. Some were based on optical illusions; a night-time rain squall or large icebergs can convince a whole ship's crew that they are seeing great black cliffs surrounded by breakers. Then there were deliberate fabrications. Captain Benjamin Morrell, "the biggest liar in the Pacific", invented Morrell Island in the 1820 s to impress his backers, yet the island remained on Chart 2683 until 1907.

Stommel, a scientist at Woods Hole Oceanographic Institute, half-apologetically dismisses his interest in the origin, history and demise of lost islands as "frivolous". He should have no such reservation. He may have entered a byway of geographical exploration, but he has made an entertaining and scholarly study of it. Besides, some imaginary islands have had far from frivolous consequences. The Mexicans put so much time, effort and money into the search for two nonexistent "gold" and "silver" islands in the Pacific that they left the serious development of California far too late. As a result, the region was so tenuously Mexican by 1848 that it all too easily slipped into American hands.

Peter J. Smith is Reader in Earth Sciences at the Open University, Walton Hall, Milton Keynes $M K 76 A A, U K$.

\section{IMAGE \\ UNAVAILABLE FOR COPYRIGHT REASONS}

"London going out of Town - or - The March of Bricks \& Mortar", by George Cruikshank (1829), reproduced from The English Landscape: Past, Present, and Future edited by S.R.J. Woodell. Publisher is Oxford University Press, price is $f 15$. 